\title{
O SOFRIMENTO PSÍQUICO DOS PROFESSORES DIANTE DAS TECNOLOGIAS DIGITAIS E A METÁFORA DA HOSPITALIDADE: (RE)PENSANDO A FORMAÇÃO DOCENTE
}

\author{
Prof. Msc. Paulo Gaspar Graziola Junior \\ Universidade do Vale do Rio dos Sinos - UNISINOS \\ pgraziola@gmail.com \\ Prof. Msc. Maria de Fátima Reszka \\ UNISINOS/ULBRA Gravataí/FACCAT \\ mfreszka@zipmail.com \\ Prof. Dra. Eliane Schlemmer \\ Universidade do Vale do Rio dos Sinos - UNISINOS \\ elianes@unisinos.br
}

\begin{abstract}
A pesquisa, vinculada ao Grupo de Pesquisa em Educação Digital - Gpe-dU UNISINOS/CNPq, tem como objetivo analisar as mudanças ocorridas no contexto da educação, diante do uso das Tecnologias Digitais (TDs) e o sofrimento psíquico advindo desse processo, para (re)pensarmos a formação docente. Como percurso metodológico, estamos realizando um levantamento bibliográfico dos últimos 20 anos em relação ao uso das TDs na escola. Para isso, procuramos articular a Teoria da Metáfora da Hospitalidade, buscando luz junto à Psicanálise, para entender por meio da escuta o sofrimento psíquico dos professores. A Hospitalidade é então o comportamento que revela o esforço humano para lidar com a incerteza que está sempre envolvida ao hospedarmos uma nova tecnologia: pode-se descobrir a nova tecnologia como um hóspede muito agradável, ou ela pode, ao contrário, se revelar um inimigo, roubando o território do hospedeiro e fazendo dele um refém, desencadeando angústias e gerando sofrimentos. O sofrimento é um entrelaçamento entre as condições subjetivas e as condições objetivas histórico-culturais, desencadeando um mal-estar docente como um sintoma psíquico, que nasce do enodamento do corpo com o discurso social e a fantasia do sujeito. Como a pesquisa encontra-se em desenvolvimento, procuramos provocar uma discussão maior sobre esses aspectos e possíveis sintomas que desse advém.
\end{abstract}

Palavras chave: hospitalidade, sofrimento psíquico, formação docente, tecnologias digitais.

\section{PSYCHOLOGICAL SUFFERING OF TEACHERS TOWARDS ELECTRONIC TECHNOLOGIES AND THE HOSPITALITY METAPHOR: (RE)THINKING THE DOCENT DEVELOPMENT}

The objectives of the current research that belongs to UNISINOS/CNPq Research Group for Electronic Education is to analyze changes occurred in the context of education, facing the use of Electronic Technologies and the psychological suffering coming from this process, for us to (re)think the development of the docent. As methodological course we are making a bibliographic review of the past 20 years in relation to the use of technologies at school. Therefore, we try to articulate the Theory of the Hospitality Metaphor seeking light from Psychoanalysis to understand through 
listening the teachers' psychological suffering. Hospitality is then the behavior that reveals the human effort to deal with uncertainty, which is always related to hosting a new technology: one can discover the new technology as a very pleasant host, as well as it can be revealed by the opposite, as an enemy, robbing host territory and making him a hostage. Thus, it can break into angst, generating sufferings. The suffering is linked to the subjective conditions and to objective historical-cultural conditions, breaking out into an unpleasant docent status as a psychological symptom that begins from the interrelation of the body with the social speech and the fantasy of the subject. As the research is ongoing, we try to cause a greater discussion about these aspects and possible symptoms approaching from those.

Key words: hospitality, psychological suffering, docent development, electronic technologies.

\section{INTRODUÇÃO}

Sabemos o quanto pode ser positivo o uso de diferentes TDs nos processos de ensino e de aprendizagem, no entanto, sabemos também o quanto isso pode parecer assustador. Hoje temos alunos invadindo a privacidade dos professores, dos colegas, fomentando fenômenos como o ciberbulliyng, gerando angústia nos envolvidos. Esses recursos tecnológicos, que a priori seriam para auxiliar e facilitar a vida das pessoas em todas as áreas, infelizmente estão sendo utilizados de maneira inconseqüente e perversa, menosprezando e insultando outras pessoas, causando gravíssimas consequiências e danos para as vítimas. Mostra-se preocupante esta nova realidade que nos descortina e acreditamos ser urgente trabalharmos temáticas como essa no âmbito da formação docente.

O desafio de refletir sobre essa temática que envolve o conhecimento desses novos sujeitos que habitam a escola, esse professor em formação e esse aluno zapeador, irão depender, não somente, da compreensão dos sofrimentos advindos da vivência de si mesmo e do outro, mas de todo um envolvimento diante das mudanças nesse contexto.

A partir disto, torna-se fundamental refletir e planejar ações sobre as seguintes questões: Que aluno é esse que temos em sala de aula hoje? O professor tem buscado formação para lidar com esse novo aluno e as tecnologias digitais? Existe sofrimento psíquico advindo disso? Como ele se manifesta? Existe violência virtual nesse processo? Aliado a isso, a escola parece ser o palco de toda essa problemática das relações interpessoais, tão intensa e frágil, onde isso se evidencia. Poderemos conceber uma educação capaz de ensinar e aprender nesse contexto?

\section{CONTEXTUALIZANDO TÉCNICA, TECNOLOGIA, SOCIEDADE EM REDE...}

O início da evolução do homem e, consequentemente, o início das primeiras sociedades foi marcado diretamente pela influência da tecnologia. Como é lembrado por Lemos (2002), podemos citar alguns exemplos, tais como: a descoberta do fogo, o cultivo da terra, a domesticação dos animais, a construção de cidades, o domínio da energia, a construção de indústrias, a conquista do espaço cósmico, as viagens aos confins da matéria e do espaço-tempo.

Lemos (2002) cita que etimologicamente o termo Técnica vem do grego tekhnè que pode ser traduzido por arte. Dessa forma, tekhnè compreende as atividades práticas, desde habilidades de contar e medir até as artes plásticas ou belas artes, consideradas estas últimas a mais alta expressão de tecnicidade humana. Assim, técnica pode ser 
definida como o procedimento ou o conjunto de procedimentos que tem como objetivo obter um determinado resultado seja no campo da Ciência, da Tecnologia, das Artes ou em outra atividade.

Complementando, Lemos (2002) cita que a partir do século XVII, a atividade técnica começa a ligar-se ao conhecimento científico, culminando esse processo no século XX por meio dos Centros de Pesquisa e Desenvolvimento, determinando desse modo a junção definitiva da ciência com a técnica. Assim,

Podemos dizer que a técnica pré-histórica é produto de uma experiência empírica do mundo, sem necessidade de explicações científicas (as primeiras ferramentas, instrumentos e máquinas). A técnica é o fazer transformador humano que prepara a natureza à formação da espécie e da cultura humana. Ela é uma provocação da natureza gerando um processo de naturalização dos objetos técnicos na construção de uma segunda natureza povoada de matéria orgânica, de matéria inorgânica e de matéria inorgânica organizada (os objetos técnicos). (LEMOS, 2002, p. 40)

O que chamamos hoje de tecnologia ou técnica moderna é justamente a naturalização dos objetos técnicos e de sua fusão com a ciência. Nesse momento, a natureza e a vida social são requisitadas como objetos de intervenções tecno-científicas.

Segundo Castells (2005), uma revolução tecnológica centrada nas tecnologias da informação e da comunicação está remodelando a base material da sociedade em ritmo acelerado. Há um movimento intenso e crescente de redes interativas de computadores, criando novas formas e canais de comunicação, moldando a vida e simultaneamente sendo moldadas por ela. Assim, a rápida evolução das tecnologias e das telecomunicações provoca mudanças em todos os setores da sociedade, contribuindo para o surgimento da chamada "Sociedade em Rede". Lemos (2002, p. 147) afirma que "hoje, rede significa uma estrutura telemática ligada a conceitos como interatividade, simultaneidade, circulação e tactilidade ${ }^{\mathrm{i}, \text {. }}$

[...] a tecnologia não determina a sociedade. Nem a sociedade escreve o curso da transformação tecnológica [...] o resultado final depende de um complexo padrão interativo [...]. A tecnologia é a sociedade, e a sociedade não pode ser entendida ou representada sem suas ferramentas tecnológicas. (CASTELLS, 2005, p. 25).

Entretanto, Castells (2005, p. 26) complementa:

sem duvida a habilidade ou inabilidade de as sociedades dominarem a tecnologia e, em especial, aquelas tecnologias que são estrategicamente decisivas em cada período histórico, traça seu destino a ponto de podermos dizer que, embora não determine a evolução histórica e a transformação social, a tecnologia (ou sua falta) incorpora a capacidade de transformação das sociedades, bem como os usos que as sociedades, sempre em um processo conflituoso, decidem dar ao seu potencial tecnológico.

Nessa sociedade em rede, emergente, o processo de transformação tecnológica expande-se exponencialmente em razão de sua capacidade de criar uma interface entre campos tecnológicos, mediante uma linguagem digital comum, na qual a informação é gerada, armazenada, recuperada, processada e transmitida. De acordo com Castells (2005, p. 50), "as novas tecnologias da informação possibilitam, ao mesmo tempo, a descentralização das tarefas e sua coordenação em uma rede interativa de comunicação em tempo real, seja entre continentes, seja entre os andares de um mesmo edifício". (p. 286)

O planeta está imerso numa cultura global que nasce com o advento dos meios de comunicação unidos às TDs, chamada Cibercultura. 
Para o sociólogo André Lemos (2006, p. 10),

[...] o desenvolvimento da cibercultura começa com a micro-informática nos anos 70, com a convergência tecnológica e o estabelecimento do personal computer (PC). Nos anos 80-90, assistimos a popularização da internet e a transformação do PC em um computador coletivo (CC), conectado ao ciberespaço.

Para Lemos (2002), a cibercultura é a associação da cultura contemporânea às TDs, aliando a técnica à vida social. São os nossos novos modos de vida permeados pela comunicação instantânea, pela rapidez da informação, pela possibilidade de intervenção e criação de novas informações que caracterizam primordialmente a cibercultura.

Lemos (2002, p. 93) apresenta que,

a cibercultura vai se caracterizar pela formação de uma sociedade estruturada através de uma conectividade telemática generalizada, ampliando o potencial comunicativo, proporcionando a troca de informações sob as mais diversas formas, fomentando agregações sociais.

Lemos (2002, p. 281) complementa ainda:

a imprensa, o rádio e a televisão nos entregam diariamente notícias dessa frente cibernética (internet, celulares, pagers, PDA, CD-Rom, realidade virtual,, etc.), como um reflexo de nossa sociedade que se torna, cada vez mais, impactada e transformada pela simulação, pela comunicação em rede e pelas micro-máquinas que colonizam nosso cotidiano.

Outra característica é que, na Cibercultura, os modos de vida antigos não são anulados, mas reconfigurados. Assim, conforme Lemos (2002), coisas que antes fazíamos de uma determinada forma, hoje tem sua lógica, espaço e tempo modificadas por conta do advento das TDs em rede. Por exemplo, para ir ao banco não é mais preciso se deslocar fisicamente. Com apenas alguns cliques é possível: transferir, depositar, comprar e pagar, enfim realizar diversas aplicações financeiras. É possível também dialogar com várias pessoas ao mesmo tempo, de diversos lugares, sem sair de casa. Na cibercultura tem-se a sensação de onipresença. As mídias de massa perdem sentido numa cultura onde todos podem publicar seus pensamentos, ideias, poesias, até mesmo para se autopromover, além de poder manipular imagens, sons, publicar, enviar, copiar e colar. A liberação desses pólos de emissão é própria das TDs e da rede, com a horizontalização do poder da emissão e recepção: a informação deixa de ser transmitida para ser dialogada. Além disso, na cibercultura, a figura do espectador quase inexiste, pois todos podem potencialmente elaborar e emitir informação ${ }^{\text {ii }}$.

Assim, a cibercultura indica um novo modelo de viver e de se relacionar com o outro. O respeito ao outro se faz imprescindível na cultura de rede, na comunicação, porque ninguém se comunica sozinho e a rede só existe na intersecção de diversos 'nós'.

Essas modificações nas formas sociais, nas práticas dessa cibercultura, trazem à tona também mudanças em relação ao cotidiano do professor, envolvidas no processo de formação e na prática desses sujeitos.

\section{COTIDIANO DO PROFESSOR FRENTE ÀS TECNOLOGIAS DIGITAIS}

Papert (1994), professor-pesquisador e um dos fundadores do Laboratório de Inteligência Artificial do MIT, foi o responsável, no final dos anos 70, pelo grande 
avanço para o uso da informática na Educação. Em seu livro "A maquina das crianças: repensando a escola na era da informática", Papert refere que não podemos esquecer a criança que existe em todos nós, e que ela não a sufocou, mantendo-a viva em sua trajetória profissional, deixando transparecer seu lado profundamente humano. Uma de suas idéias é tornar o estudante o sujeito do processo de aprendizagem e não objeto.

Corroborando com isso, Freud (1976b) afirma algo parecido, dizendo que: "Só pode ser pedagogo aquele que encontrar capacidade de penetrar na alma infantil, pois nos adultos não compreendemos a nossa própria infância”.

No final da década de 80 nasce uma nova geração que tem agregado muito apelidos, geração digital, geração de rede, geração ciber, nativos digitais, denominações que se referem a características especificas de seu ambiente ou comportamento.

Quando pensamos no homo sapiens, o homem sábio, expressão usada por Henri Bérgson, para indicar o homem, único animal inteligente em face dos demais, e no homo zappiens, aqui chamado de cidadão virtual, que sabe zapear, utilizar varias tecnologias digitais ao mesmo tempo (VEEN E VRAKKING, 2009), nos damos conta que um mundo de diferenças se configuram entre um ser e outro, entre o educador e o aluno hoje. Precisamos, então, aprofundar os estudos desses lugares ocupados, pois pouco conhecemos deles, sendo que os mesmos fazem parte do nosso cotidiano, sendo o educador da era analógica e alunos da era digital.

Dentro desse contexto, Alonso (2007) discorre sobre uma formação ao longo da vida (life-long learning) no campo da educação e da formação docente como um tema prioritário do final do século XX e principio do século XXI. Alonso (2007), ao refletir sobre os problemas e origens do debate, acerca da necessidade de uma formação permanente, destaca algumas ilusões enraizadas na tradição educativa acerca das potencialidades da formação docente:
“a) a ilusão de o profissional possuir todo o conhecimento necessário relativamente às necessidades e problemas das crianças e jovens;
b) a ilusão de que as Ciências da Educação constituem um campo coerente de conhecimento racional e aplicável que pode ser transmitido em cursos sistemáticos aos futuros professores;
c) a ilusão de que o profissionalismo docente ser a resultante mágica da formação acadêmica realizada, normalmente, de forma mais ou menos separada dos problemas e práticas quotidianas das escolas;
d) a ilusão de o profissional ser capaz de educar os alunos para a vida e o trabalho sobre os quais ele não conhece o suficiente;
e) a ilusão de o profissional ser um servidor do Estado que está acima das classes sociais, sem se envolver politicamente nas suas contradições e antagonismos. (ALONSO, 2007, p. 44)"

Nesse meio persistem o educar, e junto a isso mais ambigüidades, pois o termo na sua origem pode ser atribuído tanto a educatio, quanto a eductio. Camargo (2006) nos traz essa distinção apontando que a primeira refere-se a ações de criar, amamentar, cuidar, ensinar uma criança. Já o segundo remete à condição de botar para fora, fazer sair, tirar de dentro, enfim, dar à luz, fazendo com que possamos refletir o movimento em que estamos inseridos, colocando para dentro e auxiliando a botar para fora, deixando criar, revelando-se.

A dita "revolução tecnológica" vem mexer mais ainda nesses conceitos, pois, sabemos que o educar, que a escolarização assumia a tarefa social de transmitir o conhecimento historicamente acumulado às gerações juvenis, e o professor se constituía na principal fonte desse processo, esse possuía o acumulo cultural e os conhecimentos profissionais, que eram repassados aos alunos. Esse lugar vem sendo questionado, apontando que não há mais sentido social na função de professor alicerçado na 
transmissão de conhecimento. Reflete-se isso no campo da autoridade, colocando em jogo nossa profissão (CUNHA, 2009).

A principal função da autoridade é autorizar, autorizar a existir, a crescer, a aprender, a ser reconhecido e respeitado em sua dignidade humana, sem exclusões. A autoridade como autorização está de acordo com a etimologia do termo, (auctoritas, auctor), ou seja, aumentar o poder da vida e de afirmação pessoal, crescer, ser autor (GUILLOT, 2008). O mesmo traz as duas maneiras de ser autor em educação, uma que consiste em se pretender ser autor do outro, correspondendo à autoridade que proíbe de se tornar alguém, sendo essa uma autoridade que destrói, e outra, que autoriza o sujeito a tornar-se autônomo, sendo a autoridade que constrói.

Precisamos, dessa forma, resgatarmos a autoridade em educação, pois sabemos que a mesma está em pane. Precisamos analisar três referencias diante disso. A primeira advém de uma mudança de paradigmas em nossa sociedade, pois os modelos de identificação são outros. Hoje, os adolescentes são modelos. As atitudes em relação ao tempo, o aqui e agora governa o jogo dos desejos. A segunda diz do medo do autoritarismo diante as representações coletivas, e a ultima diz do papel do professor na atualidade (GUILLOT, 2008).

Sousa Santos (1998) também nomeia essa crise de legitimidade e de autoridade junto a nós, pois a tradição universitária já não dá conta em suas práticas, sendo questionada sistematicamente. $\mathrm{O}$ acesso a informação trouxe grandes mudanças, e essas refletem no fazer pedagógico.

Diante desse acesso e para entendermos como ocorre o processo de aceitação de uma nova tecnologia pelo sujeito, vamos utilizar a Teoria da Metáfora da Hospitalidade de Ciborraiii (2002).

\section{METÁFORA DA HOSPITALIDADE}

Na Teoria da Metáfora da Hospitalidade, proposta por Ciborra (2002), a tecnologia é tratada como um hóspede. Esse hóspede pode ser entendido como um convidado com o qual se aceita conviver ou como alguém que pode nos ser hostil. Nesse contexto, hospitalidade refere-se a tratar essa tecnologia com um olhar estranho e ambíguo, pois ao permitirmos e aceitarmos esse "hóspede", podemos considerá-lo amigo ou inimigo.

Segundo Saccol e Reinhard (2005, p.2),

a hospitalidade é então o comportamento que revela o esforço humano para lidar com a incerteza que está sempre envolvida ao hospedarmos uma nova tecnologia: durante o processo de hospedagem, pode-se descobrir a nova tecnologia como um hóspede muito agradável, ou ela pode, ao contrário, se revelar um inimigo, roubando o território do hospedeiro e fazendo dele um refém.

Ciborra (2002) coloca que lidar com essa incerteza, essa ambigüidade, dessa forma, refletir acerca do que a tecnologia representa, pode ser considerada a essência da hospitalidade. Caso contrário, esse processo de hospedagem se configuraria em um processo vazio, passivo e insignificante. Assim, a verdadeira hospitalidade pode ser considerada como o comportamento que revela o esforço humano em lidar com a incerteza e o mistério de se hospedar um estranho.

Assim, ao adotarmos uma tecnologia e a hospedarmos no nosso dia-a-dia é preciso muitas vezes readaptarmos nossos comprometimentos perante a nova tecnologia 
(organização, autonomia, entre outros), processos de trabalho e rotinas. Ao redefinirmos, estamos reinterpretando nossas próprias identidades.

Sobre esse aspecto, Ciborra (2002) coloca que devemos considerar que a hospitalidade pode implicar uma negociação entre a novidade trazida pelo hóspede (mundo externo) e o mundo do seu contexto, interno (sua organização, sua prática cotidiana). É justamente nesse confronto entre mundo interno e externo, na hospedagem da tecnologia (hóspede), que podemos reforçar, impor ou ainda mudar nossas identidades.

Esse processo é cheio de tensões, pois tanto o hospedeiro quanto o hóspede podem se tornar reféns um do outro. Assim, este é um tipo de relacionamento que deve ser baseado em confiança.

A Teoria da Metáfora da Hospitalidade visualiza esse processo de adoção da nova tecnologia como um processo de aprendizagem que envolve tentativa e erro, improvisação e construção de conhecimento de maneira informal. Podem ocorrer, nesse processo de "hospedagem", adaptações, novos usos da tecnologia não previstos quando foi criada, improvisação, dentre outros. Ciborra (2002) coloca que as pessoas vão interagir e procurar adaptar a tecnologia, tornando familiar o que é estranho.

Saccol e Reinhard (2005, p.2) colocam que

como resultado desse processo, a tecnologia por "ir a deriva" (drift), isto é, ela pode servir a objetivos não previstos, ser usada de forma distinta do que foi planejado, ou sofrer ajustamentos de acordo com o contexto real no qual ela está sendo aplicada. É somente através da interação contínua entre pessoas e tecnologia que se poderá verificar os resultados efetivos da adoção.

A metáfora da hospitalidade chama ainda a atenção para as emoções, também conhecidas como estados-de-espírito $\left(\operatorname{moods} s^{i i i i}\right)$ dos sujeitos durante o processo de hospitalidade de uma nova tecnologia.

Saccol (2005) coloca ainda que as pessoas desenvolvem um apego emocional com eventos e artefatos (no caso os dispositivos móveis) que não deve ser ignorado. Assim, o processo de hospitalidade chama a atenção para as características biográficas, éticas e históricas das pessoas envolvidas na adoção de uma nova tecnologia.

Saccol e Reinhard (2006) descrevem as principais proposições relacionadas com a Metáfora da Hospitalidade, quais sejam:

- Ao hospedarmos uma nova tecnologia nós reinterpretamos nossas identidades.

- Hospedar uma nova tecnologia envolve aprender fazendo e improvisação.

- Durante o processo de hospedagem a tecnologia poderá ir à deriva.

- Hospitalidade envolve humores e emoções.

- Hospitalidade diz respeito à apropriação e cuidado.

- Hospitalidade envolve cultivo.

- Não podemos esquecer o caráter dúbio da tecnologia: a tecnologia pode se transformar num inimigo.

Por fim, a hospitalidade implica uma apropriação e interesse das pessoas pela nova tecnologia, tornando-se, dessa forma, uma hospedagem bem sucedida, o que, consequentemente, implica o desaparecimento dessa tecnologia na vida diária do sujeito, integrando-se às rotinas e contextos de trabalho de forma que com o tempo tende a se naturalizar. Por meio da Teoria da Hospitalidade podemos interagir com a nova tecnologia sem seguir passos pré-definidos, lidando assim com o desconhecido e com o imprevisível, como se configuram as práticas do dia-a-dia. $\mathrm{O}$ espaço que essa nova tecnologia irá ocupar ou não deverá ser constantemente refletido. 


\section{SOFRIMENTO PSÍQUICO}

Segundo Reszka (2005), existe uma inversão no papel de autoridade, pois não há diferença entre a autoridade do professor em relação ao que fazer com o aluno e em relação à autoridade que o aluno vem exercendo na escola diante do professor. Nessa perspectiva, os professores sentem-se perdidos, frustrados e amedrontados diante a autoridade perdida, e, consequentemente, da agressividade e violência que têm surgido nos espaços escolares.

Todo esse contexto descreve um professor permeado por sofrimento, angústia incertezas e impasses. O sofrimento é um entrelaçamento entre as condições subjetivas $\mathrm{e}$ as condições objetivas histórico-culturais (AGUIAR \& ALMEIDA, 2008). As mesmas autoras apontam para um mal-estar docente como um sintoma psíquico, que nasce do enodamento do corpo com o discurso social e a fantasia do sujeito.

Um sintoma psíquico deve ser entendido como um fenômeno subjetivo que constitui não um sinal de doença, mas a expressão de um conflito inconsciente (CHEMAMA, 1995). O sintoma é, então, uma formação do inconsciente, estruturado como uma linguagem; é a verdade do sujeito que surge na falha do saber e que o docente manifesta em seu sofrimento, gritando, fazendo sintoma, metaforizando sua angustia, que muitas vezes não é reconhecida.

Em Mal-estar na civilização (FREUD, 1976b) já referia ser o trabalho uma das fontes do mal-estar na cultura, pois gera conflitos no sujeito e uma sensação de estranhamento e infelicidade, pois o fato de haver comprometimento no relacionamento com os outros desencadeia um dos maiores sofrimentos.

Em Inibição, Sintoma e Angústia (FREUD, 1976a), chamou de subjetividade de desamparo, que se refere a angústia com as relações interpessoais, sociais e a toda estrutura do sujeito, e sabemos que esse desamparo é o que instaura o mal-estar na contemporaneidade.

Esteve (1999) descreve a expressão mal-estar docente para entendermos os efeitos permanentes, de caráter negativo, que afetam a personalidade do educador como resultado das condições psicológicas e sociais em que exerce a docência devido à mudança social acelerada.

Nota-se com isso, que o professor vem adoecendo, e estamos parados no tempo, sem repensarmos nosso cotidiano, sem articular as dimensões do ensino e pesquisa nos lugares e espaços de formação, conforme nos aponta Cunha (2009).

Colaborando, Guillot (2008, p.118) nos diz que a formação está no centro do problema: “[...] As necessárias analises criticas não devem limitar discursos como o formalismo de boa qualidade cultural: são as praticas de ensino que devem ser iluminadas."

\section{FINALIZANDO O QUE PRECISA SER CONSTANTEMENTE REFLETIDO...}

Com o intuito de trazer algumas indagações acerca dos professores em formação, no âmbito das tecnologias digitais, podemos compartilhar com todos vocês as mudanças paradigmáticas que estamos envoltos, desde os meados do século XX, com o advento da bomba atômica e da tecnologia digital, demarcando dessa forma $\mathrm{o}$ nascimento da pós-modernidade como uma época de transição de algo.

A condição de professor e sujeito hoje, hospedando ou não a tecnologia, apontanos que pode ou não ocorrer sofrimento. É importante trazermos à tona que, hospedar essa tecnologia, envolve um constante "dar conta" do acesso com o mundo, restringindo 
assim, a privacidade do sujeito, marcando fraturas quanto ao tempo, ao espaço e à ética desse professor e sujeito. Ao mesmo tempo, não hospedar a tecnologia, é sentir-se excluído desse processo, influenciando na sua forma de encarar a escola e esses alunos que trabalham diariamente com essas tecnologias digitais, gerando sofrimento e angústia quando ele passa a refletir sua prática no mundo, estando muitas vezes refém dessa tecnociência.

Nesse contexto, precisamos rever como as instituições formadoras estão abrindo espaço para essas discussões, sobretudo diante da Pedagogia Universitária, das matrizes curriculares atuais e o sofrimento que advêm desse processo, como um sintoma social abrangente.

\footnotetext{
${ }^{\text {i }}$ Caráter próprio da condição humana pelo qual cada homem se encontra sempre já comprometido com uma situação não escolhida.

ii Conforme Castells (2005, p. 45), "Informação são dados que foram organizados e comunicados".

iii Cláudio Ciborra foi professor de Sistemas de Informação da London School of Economics. Tem amplas experiências nas áreas de comércio eletrônico, aprendizagem organizacional. Nasceu em 1951 e faleceu em 2005.

iiii As pessoas entram em situações - incluindo o processo de adoção de uma inovação - com um determinado estado-de-espírito que é elusivo, não pode ser controlado ou mesmo representado em símbolos (por exemplo: medo, ansiedade, felicidade, pânico ou tédio). (SACCOL, 2005, p. 151)
}

\section{REFERÊNCIAS}

AGUIAR, R \& ALMEIDA, S. F. C. Mal-estar na educação: o sofrimento psíquico dos professores. Curitiba: Juruá Editora, 2008.

ALONSO, L. Perfil profissional e projeto de formação. In: De uma escola a outra Temas para pensar a formação inicial de professores. Amélia Lopes (Org.) Porto: Edições Afrontamento, Portugal, 2007.

CAMARGO, A.C. S de. Educar: uma questão metodológica? Proposições psicanalíticas sobre o ensinar e o aprender. Petrópolis: Vozes, 2006.

CASTELLS, Manuel. A sociedade em rede. 8. ed. São Paulo: Paz e Terra, 2005.

CHEMAMA, R. Dicionário de Psicanálise. Porto Alegre: Artes Médicas, 1995.

CIBORRA, C. The labyrinths of information: challenging the wisdom of systems. New York: Oxford Press, 2002.

CUNHA, M. I. A educação superior e o campo da pedagogia universitária: legitimidades e desafios. In: Isaia \& Bolzan (orgs) Pedagogia Universitária e desenvolvimento profissional docente. Porto Alegre: Edipucrs, 2009, v.4, p.351-374.

ESTEVE, J.M. Mudanças sociais e função docente. In: Nóvoa, A (org) Profissão Professor. Lisboa: Porto, 1999, p.93-122.

FREUD, S. Inibição, sintoma e angustia. In: Edição Standard das Obras Completas de Sigmund Freud. V.XX, Rio de Janeiro: Imago, 1976a. 
FREUD, S. Mal-estar na civilização. In: Edição Standard das Obras Completas de Sigmund Freud. V. XXI, Rio de Janeiro: Imago, 1976b.

GUILLOT, G. O resgate da autoridade em educação. Porto Alegre: Artmed, 2008.

LEMOS, A. Cibercultura, tecnologia e vida social na cultura contemporânea. Porto Alegre: Sulina, 2002.

- Ciberespaço e tecnologias móveis: processos de territorialização e desterritorialização na cibercultura. COMPÓS, Bauru, jun. 2006.

MURTA, C. Magistério e sofrimento psíquico: contribuição para uma leitura psicanalítica da escola. In: 3 COLOQUIO DO LEPSI IP/FE-USP, São Paulo, 2001. Disponível em <http://www.proceedings.scielo.br/scielo.php?script= sci_arttext\&pid=MSC0000000032001000300031\&lng=en\&nrm=abn>. Acesso em: 12 mai. 2010.

PAPERT, S. A máquina das crianças: repensando a escola na era da informática. Porto Alegre: Artes Médicas, 1994

RESZKA, M. F. Angustia docente e violência no ambiente escolar. Revista Textual, v.1, n 5, Porto Alegre: Sinpro RS, 2005, p.22-30.

SACCOL, A. A Teoria da Hospitalidade e o processo de adoção de Tecnologias da Informação Móveis e Sem Fio. Tese de Doutorado. Programa de Pós-Graduação em Administração, Faculdade de Economia, Administração e Contabilidade da Universidade de São Paulo, São Paulo, 2005.

REINHARD, N. Processo de Adoção e Decorrências da Utilização de Tecnologias de Informação Móveis e Sem Fio no Contexto Organizacional. In: XXIX EnANPAD, 2005, Brasília. Anais do XXIX EnANPAD 2005, v. 1, 2005, p. 1-16.

SANTOS, B DE S. Pela mão de Alice: O social e o político na pós-modernidade. Porto: Afrontamento, 1998.

VEEN, W \& VRAKKING, B. Homo zappiens: educando na era digital. Porto Alegre: Artmed, 2009. 